\title{
Laparoscopic management of an ovarian steroid cell tumor, not otherwise specified causing virilization and amenorrhea: A case report
}

\author{
Mohamed A Ben Haj Hassine ${ }^{* 1}$, Issam Msakni ${ }^{2}$, Haythem Siala ${ }^{1}$, Radhouane Rachdi ${ }^{1}$ \\ ${ }^{1}$ Department of Gynaecology and Obstetrics, Military Hospital, Tunis, Tunisia \\ ${ }^{2}$ Department of Pathology, Military Hospital, Tunis, Tunisia
}

Received: August 11, 2015

DOI: $10.5430 /$ crcp.v3n1p10
Accepted: October 12, $2015 \quad$ Online Published: October 28, 2015

URL: http://dx.doi.org/10.5430/crcp.v3n1p10

\begin{abstract}
Steroid cell tumors account for less than $0.1 \%$ of all ovarian tumors. There are three steroid cell tumor subtypes: steroid cell tumor not otherwise specified (NOS), stromal luteoma and Leydig cell tumor. Steroid cell tumor, NOS, is the most common type and has malignant potential. We report the case of 39-year-old woman complaining of pelvic pain and amenorrhea. Physical examination revealed hirsutism. Transvaginal ultrasound showed an hyperechogenic homogenous cyst of 4 centimeters of the left ovary without signs of malignancy. The right adnexa was normal. MRI imaging showed a left ovarian mass of $34 \mathrm{~mm} \times$ $30 \mathrm{~mm}$ with enhancement after intravenous gadolinium. A left salpingo-oophorectomy was carried out with peritoneal cytology by laparoscopy. Histology concluded to a steroid cell tumor not otherwise specified, which had a low malignant potential. After 2 months, we noticed the regression of hirsutism and the patient had normal menses. She's currently pregnant at 6 months of gestation. A complete surgical staging will be achieved after childbearing.
\end{abstract}

Key Words: Ovary, Ovarian neoplasm, Hirsutism

\section{INTRODUCTION}

Steroid cell tumors are uncommon sex cord-stromal ovarian tumors. Scully was the first to individualize this entity in 1979. ${ }^{[1]}$ The incidence of steroid cell tumors is less than $0.1 \%$ among all ovarian tumors. ${ }^{[2]}$ Steroid cell tumors include 3 subtypes: steroid cell tumor not otherwise specified (NOS), stromal luteoma and Leydig cell tumor. Steroid cell tumors, NOS, account for one-half of all ovarian steroid cell tumors. ${ }^{[3]}$ The proportion of tumors that are malignant has ranged from $25 \%$ to $43 \%$. Surgery is the main treatment for steroid cell tumors, NOS. ${ }^{[4]}$ We report the case of a 39years-old woman with a steroid cell tumor, NOS, causing amenorrhea and hirsutism.

\section{Case presentation}

We report the case of a 39-years-old woman admitted in the department of gynecology for pelvic pain. In her gynecological history, her menses were irregular for the past three years then she noticed an amenorrhea for one year. In physical examination, hirsutism was noticed, interestingly these areas: beard, inner thigh and the abdomen (see Figure 1), but she hadn't neither acne nor voice modifications.

Biologic analysis revealed normal values of blood count, renal function, and glucose and tumor markers of the ovary

\footnotetext{
*Correspondence: Mohamed A Ben Haj Hassine; Email: amine.benhassine@planet.tn; Address: Department of Gynaecology and Obstetrics, Military Hospital of Tunis, MontFleury - 1008 - Tunisia, Tunis, Tunisia.
} 
(CA-125, carcinoembryonic antigen, CA 19-9). Transvaginal ultrasound examination revealed a hyperechogenic homogenous cyst of 4 centimeters of the left ovary without signs of malignancy. The right ovary was normal. MRI imaging showed a left ovarian mass of $34 \mathrm{~mm} \times 30 \mathrm{~mm}$ with enhancement after intravenous gadolinium. Pelvic and paraoartic lymph nodes weren't invaded (see Figure 2).
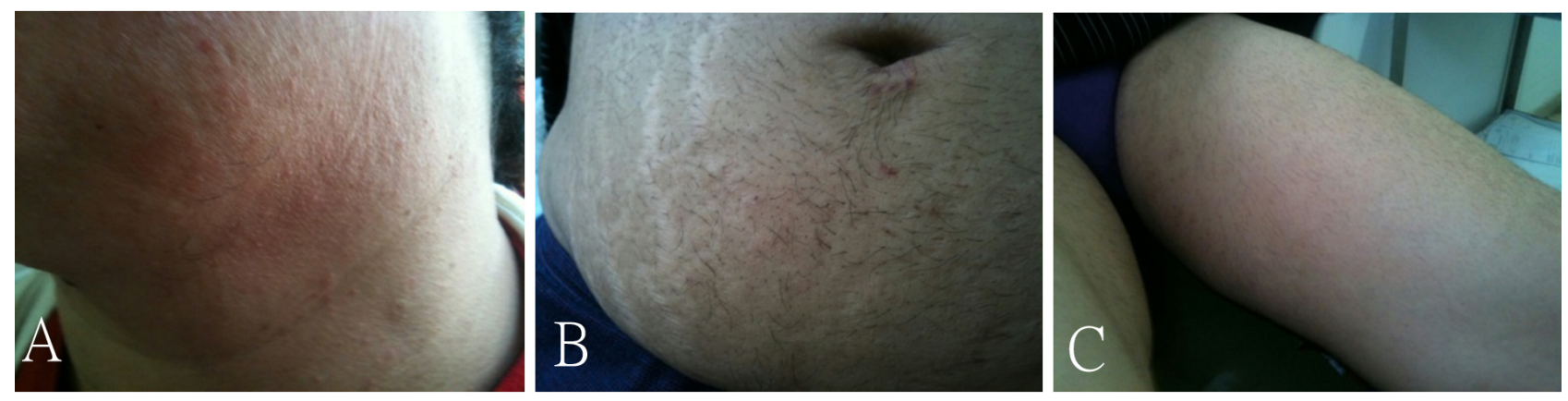

Figure 1. A: Beard hirsutism; B: Abdomen increasing hair; C: thigh increasing hair
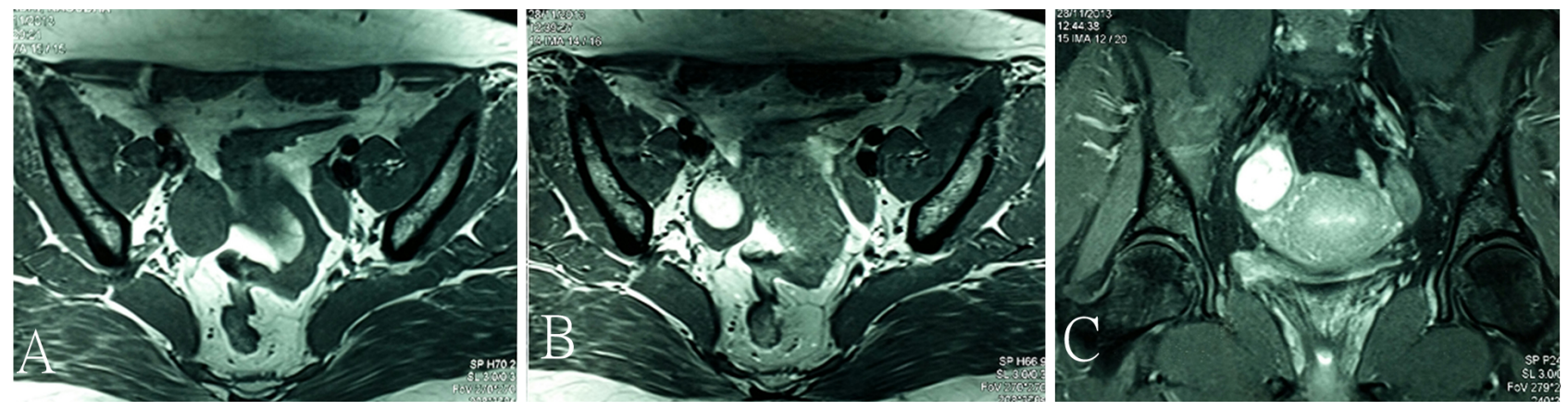

Figure 2. MRI pelvic imaging. A: ovarien left mass; B: enhancement after intravenous gadolinium; C: ovarian mass of $34 \mathrm{~mm} \times 30 \mathrm{~mm}$

On laparoscopy, the exploration of abdominal cavity showed neither ascites nor peritoneal implants. A left salpingooophorectomy was carried out with peritoneal cytology. The patient left our department after 24 hours with no complications.

Histology concluded to steroid cell tumors not otherwise specified, which had a low malignant potential. The peritoneal cytology didn't show any neoplastic cells (see Figure 3).

Two months after surgery, we noticed the regression of hirsutism and the patient had normal menses. Her serum CA 125 and hormone (testosterone, androstenedione) levels were within normal range. She's currently pregnant at 6 months of gestation. During pregnancy, the follow-up evaluation included in addition to prenatal care: ultrasound examination of the remaining ovary and measurement of sex hormone levels. There was no recurrence of the disease and the fetus had a normal growth.

Although the tumor had a low malignant potential, we de- cided to achieve a complete surgical staging after childbearing for the patient do not want to preserve her fertility after this pregnancy. The second operation will include: right salpingo-oophorectomy, infracolic omentectomy, multiple peritoneal biopsies, and pelvic-paraaortic lymph node sampling.

\section{Discussion}

There are three steroid cell tumor subtypes: steroid cell tumor NOS, stromal luteoma and Leydig cell tumor. The cell lineage of the steroid cell tumor NOS is not defined and they cannot be categorized as either stromal luteomas or Leydig cell tumors. Steroid cell tumor, NOS, is the most common type and has malignant potential. It is associated with hirsutism and virilization in half of cases. Young patients are the most affected by these tumors, which are usually unilateral. ${ }^{[5]}$ There are few cases in the literature with less than 40 reported cases found via pubmed search. Many recent cases were reported in asian ethnic group. ${ }^{[3,6,7]}$

Pathological examination is essential for diagnosis. Macro- 
scopically, the tumor has regular borders, well circumscribed lated cytoplasm. They were arranged in nests associated to and solid, with a lobulated or nodular appearance. Microscop- a rich vessels development. Li and al described other types ically, the tumor cells are round or polygonal with distinct cell borders, central nuclei and prominent nucleoli. ${ }^{[8]}$ In our case, most tumor cells were polygonal with abundant vacuoof neoplastic cells; eosinophilic cells whose cytoplasm was granular. ${ }^{[8]}$

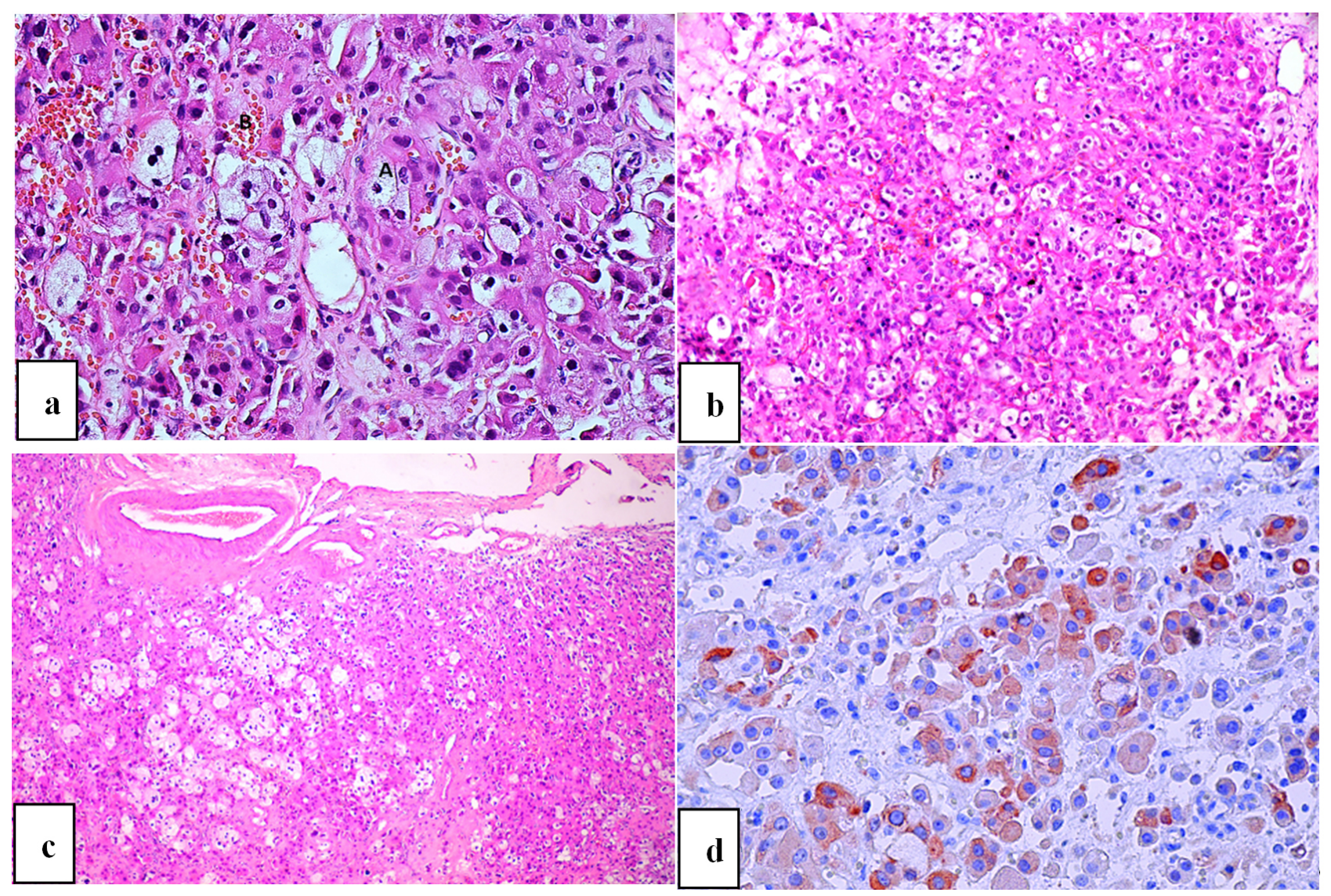

Figure 3. Histopathological photos of steroid cell tumor not otherwise specified: (a) $\mathrm{HE} \times 400$ : (A) Large polygonal cells arranged in nests; (B) Vascular characteristic: secreting tumor. (b) $\mathrm{HE} \times 250$ : clear cytoplasm and eosinophilic cells. (c) HE $\times 100$ : well circumscribed neoplastic proliferation distant from ovarian hilum. (d) IHC $\times 400$ : Anti-Inhibin Antibody was strong positive in cytoplasm.

The treatment is mainly surgical. It is recommended that ovarian steroid cell tumors, NOS, are managed surgically like other ovarian stromal tumors. ${ }^{[4]}$ A surgery preserving fertility should be considered in young women with low stage tumor, as in our case. Unilateral salpingo-oophorectomy and staging are sufficient, especially in low malignant potential tumors without lymph nodes invasion on MRI. For women who have completed childbearing, total abdominal hysterectomy with bilateral salpingo-oophorectomy and complete surgical staging is indicated. As these tumors are diagnosed in an early stage, their response to adjuvant therapy isn't known. Although, gonadotropin releasing hormone agonist (GnRHa) therapy may be prescribed postoperatively or as adjuvant therapy for recurrent tumors. ${ }^{[4]}$

In our case, the patient had amenorrhea and hirsutism for one year. This case had presented to us diagnostic difficulties that have been partially resolved by imaging techniques: ultrasounds and MRI. Diagnostic difficulties were the presumption of benignity or malignancy. In our opinion, laparoscopy has, in this case, its place to explore the abdominal cavity and perform the salpingo-oophorectomy. Pathological evaluation was essential for the diagnosis of malignancy. 


\section{REFERENCES}

[1] Scully RE. Atlas of Tumor Pathology. Armed Forces Institute of Pathology; Washington, DC, USA: 1979. Tumors of the ovary and maldeveloped gonads; pp. 215-220. (Second Series Fascicle 16).

[2] Jiang W, Tao X, Fang F, et al. Benign and malignant ovarian steroid cell tumors, not otherwise specified: case studies, comparison, and review of the literature. J Ovarian Res. 2013; 22(6): 53. PMid: 23870399. http://dx.doi.org/10.1186/1757-2215-6-53

[3] Kim YT, Kim SW, Yoon BS, et al. An ovarian steroid cell tumor causing virilization and massive ascites. Yonsei Med J. 2007; 48: 142-6. http://dx.doi.org/10.3349/ymj . 2007.48.1.142

[4] Chung DH, Lee SH, Lee KB. A case of ovarian steroid cell tumor, not otherwise specified, treated with surgery and gonadotropin releasing hormone agonist. J Menopausal Med. 2014; 20(1): 39-42. http://dx.doi.org/10.6118/jmm.2014.20.1.39
[5] Mizoguchi M, Minami S, Yamamoto M, et al. Ovarian steroid cell tumor, not otherwise specified producing testosterone. J Obstet Gynaecol Res. 2014; 40(9): 2081-5. http://dx.doi.org/10.1111 $/$ jog. 12467

[6] Oh JR, Cho SH, Yoon DK, et al. Laparoscopic management of asymptomatic ovarian steroid cell tumors, not otherwise specified: A case report and literature review. Korean J Obstet Gynecol. 2006; 49: 933-8.

[7] Lee JS, Kim BR, Lee HC, et al. A case of ovarian steroid cell tumor, not otherwise specified with hypertension, obesity, ascites and elevated CA 125. Korean J Obstet Gynecol. 2008; 51: 1164-9.

[8] Li K, Zhu F, Xiong J, et al. A rare occurrence of a malignant ovarian steroid cell tumor not otherwise specified: A case report and literature review. Oncol Lett. 2014 Aug; 8(2): 770-4. http: //dx.doi.org/10.3892/ol.2014.2233 